\section{Tres preguntas para arquitectos}

Santiago, septiembre de 2004.

\section{Apreciado amigo:}

La revista $A R Q$ está preparando un número monográfico sobre la profesión del arquitecto.

Les estamos mandando tres preguntas a Ud. y a otros arquitectos, que nos parecen adecuadas para generar un conjunto de respuestas que darán consistencia a una visión de la profesión en Chile. Entre los arquitectos consultados hay de diferentes generaciones y de varias universidades.

Una edición de este conjunto de respuestas se incluirá en la revista ARQ de diciembre de 2005, dedicada a "La profesión".

Esperando con mucho interés su participación lo saluda cordialmente,

Montserrat Palmer Directora Ediciones ARQ.

1. ¿Cuáles serán los nuevos roles del arquitecto en la próxima década? AAV arquitectos (Rodrigo Amunátegui, Cristóbal Amunátegui y Alejandro Valdés) : Analizando el panorama actual de la arquitectura chilena, vemos un considerable número de obras y proyectos que sitúan a Chile en un buen nivel, al menos en el contexto sudamericano. Sin embargo, podríamos enmarcarlas dentro de un reducido campo: son el resultado de encargos muy especiales en pequeña escala. Podríamos seguir explorando esta dirección y posiblemente encontraríamos nuevas claves constructivas, materiales y formales: continuaríamos desarrollándonos en un ámbito conocido y cómodo.

Si estamos conscientes de la libertad que tenemos como arquitectos de actuar en distintos frentes y direcciones, parece interesante tratar de ampliar nuestro campo de acción buscando diferentes modos de operar. La búsqueda de nuevos interlocutores que sean capaces de acoger y promover nuestras iniciativas, la autogestión de proyectos de mayor envergadura que afecten positivamente a un mayor número de personas, son caminos que debemos desarrollar.

Albert Tidy: Evidentemente el desequilibrio entre la amplia oferta de profesionales y las oportunidades existentes, crea una arena mucho más competitiva donde prevalecen aquellos más calificados en las áreas tradicionales del oficio. Si bien el sistema de selección natural puede considerarse perverso, en la práctica tiene un efecto positivo, ya que eleva el estado de la arquitectura.

Pienso que en los próximos 10 años el rol del arquitecto se expandirá junto con su oferta, reconquistando terrenos que tradicionalmente le pertenecieron como autoridad de la ciudad y también conquistando nuevos territorios de acción como mediador entre el mundo abstracto y la realidad física. Quisiera creer que el beneficio de la arquitectura llegará a un universo más amplio de usuarios y que dejará de ser un lujo reservado para unos pocos.

Arturo Torres: ...quedarse sólo en lo que se denomina arquitectura sería una deseconomía humanista. Una tarea pendiente en este sentido es el acercamiento utopía-praxis, muy necesario luego de la crisis del pensamiento globalizante en el actual predominio del neoliberalismo. Un camino posible es la práctica de la innovación, la creación del artista-ingeniero y la configuración arte-ciencia; en definitiva, la desaparición de la profesión, ya que no importa en qué área ésta se ejerza. Lo importante -tomando las palabras de Cortázar-no es "la literatura sino el futuro del hombre". Si a pesar de esto se desea salvar esta tradición de enseñanza de producción cultural del dominio futuro de los ingenieros ambientales, se debe aprovechar el pensamiento caótico como $a$-método de producción, pero ¿qué importaría el arquitecto o la arquitectura si el medio físico mejora y hay personas, sean quienes sean, que lo hacen mejorar?

Carolina Del Campo: Existe un rol de los arquitectos que se debería fortalecer: docencia para los no arquitectos, para que la arquitectura y el urbanismo sean parte de la cultura general no sólo desde la visión historicista. Debemos generar interés en la opinión pública por la calidad de vida, para poder tener ciudadanos demandantes y clientes críticos. Sería interesante que no sólo los arquitectos estuvieran preocupados del patrimonio, de la renovación urbana y de las nuevas formas de habitar.

Cristián Pino: El ser arquitecto para uno no sirve. La arquitectura se cimenta en el sentido común, en el bien integrado. La arquitectura es una profesión de encuentro. De intereses, de recursos, de valores, quizás por eso permanece en constante crisis, pues en el hombre hasta ahora ha prevalecido el dominio como causa. El objeto de la arquitectura está en el cuerpo social, que ha sedimentado en las ciudades. Para generar renovación urbana inevitablemente tiene que generarse primero renovación del tejido social, con propósitos comunes.

Enrique Del Río: El arquitecto es el que cuida el total de lo involucrado en una construcción; aspiraciones del cliente, construcción, negocio, ciudad. ¿ Y cómo lo cuida? desde lo propio. $\mathrm{He}$ visto que esto es lo que más valoran los clientes, la municipalidad y los usuarios, que uno sea arquitecto y no ingeniero o economista.

A lo mejor esto no es nuevo, ha sido siempre así, pero al ver la rapidez con que se hacen los proyectos, cómo se cambian los barrios, la cantidad de obras que hace una misma oficina, toda esa eficiencia se traduce en un descuido de la relación con la calle y la geografía, con el propio sitio, y con los interiores.

Héctor Valdés: No veo ninguna posibilidad -ni tampoco interés o conveniencia alguna- en que el arquitecto pueda asumir en el futuro nuevos roles, más allá de los que hasta hoy aparecen como propios de la profesión. Algunos de ellos ni siquiera son debidamente atendidos, como el urbanismo, la estructuración y la construcción. Creo que el énfasis habría que ponerlo en reforzar la formación del arquitecto en todas las materias en que su accionar aún se ejerce, capacitándolo para que pueda asumir su papel con mayor eficiencia y prestancia y ganar (o mejor dicho recuperar) niveles de mayor credibilidad y respetabilidad profesionales.

Miguel Eyquem: Hace años Rem Koolhaas decía que en un edificio de más de 50 pisos el arquitecto no tenía cabida, éste era un territorio de la pura tecnología y del cálculo matemático. El arquitecto, tan próximo al ingeniero calculista, no tiene nada que hacer cuando la estructura comienza a transformarse en un interior habitable sólo poniendo en obra todos los recursos obligados por el exigente estándar técnico de hoy en día ( ¿y la reglamentación?). El joven arquitecto alemán Jürgen Mayer, quien ganó el año 2003 el premio Mies Van der Rohe, y a quien conozco en su propio medio, se dedica al diseño de los detalles más finos y más pequeños de su construcción: la empuñadura de una puerta, sus quicios, las barandas, la complejidad que puede alcanzar una ventana y sus ventilaciones. Él piensa que desde ahí, desde estos pequeños hechos espaciales, le da el tono al edificio, lo tiñe de su creatividad, de su sentido de fineza. También es un gran músico. Esto para meditar. Renato D'Alençon: Mi visión es pesimista. Veo que nuestra profesión se especializa y a medida que lo hace cede espacios a otros profesionales. Sólo tangencialmente participamos en cuestiones como la ciudad, en la que hoy los arquitectos no jugamos roles centrales; o como la tecnología de la construcción, de la que nos separa la complejidad de los sistemas constructivos o de instalaciones que avanzan sin que participemos 
de manera sustantiva.

Está asentada para nuestra desgracia una sola manera de ser arquitecto: el perfil casi único del arquitecto de boutique, diseñador-artesano-artista, al que todos aspiramos por formación o por vanidad. A medida que las áreas del oficio que se traslapan con otras disciplinas se profundizan y crecen, nos mantenemos en la parcela del diseño que es cada vez más pequeña.

Marco Polidura: Desde un punto de vista más particular, me parece que tenemos una deuda con el desarrollo tecnológico. Existe, salvo algunas excepciones, una relación muy poco crítica con el mundo de la técnica y los materiales, sin un cuestionamiento; es decir los usamos y punto.

Sebastián Irarrázaval: La oficina tradicional a cargo de todo el proceso se fragmentará en pequeñas unidades especializadas. Veremos oficinas de arquitectura dedicadas a preparar anteproyectos y otras a generar los documentos para su construcción. También las habrá dedicadas a aprobar proyectos municipales o abocadas a hacer el seguimiento de la construcción. A esto se sumará el rol de arquitecto asesor, vinculado a temas como iluminación, acústica, seguridad, sustentabilidad, etc.

Otro rol importante será el vinculado a la simulación digital de espacios y que tendrá su campo de acción en la industria del entretenimiento. Hoy en día los mejores dibujantes de los estudios Disney y Pixar son formados en escuelas de arquitectura norteamericanas. Por último, no cabe duda que un rol fundamental será el de reproductor de la disciplina. Cada vez veremos más arquitectos dedicados a formar arquitectos.

2. En relación a las expectativas que usted tenía al egresar, ¿cómo evalúa la actual situación del ejercicio profesional?

$A A V$ arquitectos: Comenzar el ejercicio profesional de modo independiente, ¿̇tiene algún sentido? Obviamente pensamos que sí al optar por esa alternativa. Por supuesto que el entusiasmo inicial es bastante voluntarioso y porfiado; uno está dispuesto a asumir riesgos y compromisos que por momentos parecen insólitos.

Albert Tidy: El ejercicio local de la profesión es muy libre. Comparado a otras realidades, en Chile se puede ejercer inmediatamente después de la titulación, lo cual incide en la posibilidad de hacer obra tempranamente. En lo personal me siento privilegiado de poder trabajar de manera independiente en un lugar donde queda mucho por hacer, combinando academia y práctica. Creo que hacer arquitectura tiene que ver con un ejercicio de persistencia, convicción personal y resistencia al medio, pues en la ruta de un encargo siempre existen externalidades negativas que atentan contra la obra y que frecuentemente se utilizan como atenuantes de un mal resultado. Arturo Torres: ...el problema es la necesidad de un poder al que no se tiene acceso, el poder necesario para costear obras que resultan extremadamente caras para el ciudadano común. Para esto es necesario el desarrollo de estrategias ligadas a la gestión y administración de recursos productivos. ¿Por qué aquellos que tienen estas herramientas no las enseñan en las escuelas de arquitectura? Particularmente siento que tengo que volver a estudiar para poder ejercer, porque si estamos hablando de hacer Arquitectura como arte moderno, y no de hacer infraestructura a secas, entonces hacer una obra de Arquitectura con mayúscula es una empresa que aún desconocemos.

Bernardo Valdés: La creciente escisión entre la arquitectura y lo que exige el entorno de ella pone en un permanente conflicto al arquitecto, haciendo que, por un lado, se mantenga en un pequeño limbo ajeno a ciertas realidades $\mathrm{y}$, por otro, sea una constante víctima de las circunstancias.

Enrique Del Río: No podría echarle la culpa a nadie cuando las cosas no han quedado bien, ha sido mi responsabilidad.

Veo dos presiones muy fuertes en el ejercicio de mi profesión; una en relación con el dinero que espero recibir y hasta dónde cedo o soy capaz de perder el trabajo, y por otro lado la presión a aspirar ser reconocido por los pares, cosa que se transforma a veces en el centro del asunto. Si bien es un problema personal, creo que afectan íntimamente a la obra; en el primer caso, esa presión se siente en lo que se podría llamar la convención comercial y social, y en el segundo en las convenciones arquitectónicas del momento, que son las peores porque no se notan tanto y son más bonitas. Ambas atentan contra un trabajo original. Detrás de esto hay un problema ético.

Federico Elton: Al egresar como arquitecto el año 69 tenía claro que mi formación había sido bastante mediocre. Quizás, por los tiempos que vivíamos, lo que realmente nos formó como arquitectos fue el trabajo en oficinas particulares donde tenían la paciencia de enseñarnos incluso a dibujar. Egresar de la universidad en esa época era incierto en cuanto a formar oficinas propias, sin embargo mi generación logró insertarse relativamente bien y desarrollarse profesionalmente, logrando a partir de esa época una especialización en nuevas áreas como prefabricación, industrialización, paisajismo y otras. Hago por tanto una evaluación positiva, a pesar de la deficiente formación universitaria.

Héctor Valdés: ¿Cuales eran mis expectativas al egresar? (1940)

Se podrían resumir en: ejercer la profesión con independencia, con corrección, asumiendo la función social que entonces se le asignaba y la responsabilidad consiguiente; y, por supuesto, vivir de los ingresos que generara. En relación a esas expectativas me parece que el ejercicio profesional ha ido perdiendo su independencia, y por consiguiente se ha desvalorizado notoriamente su jerarquía en cuanto servicio requerido y respetado por la sociedad.

Hasta 1960 e incluso 1970, el arquitecto en una obra era no sólo el proyectista: era el Director de la Obra, era el representante del cliente, con plena autoridad sobre el constructor y la obra. En esos años el constructor, que normalmente actuaba en calidad de prestador de servicios, fue transformándose en lo que es hoy: empresariofinancista-constructor-cliente perdiendo el arquitecto su posición de autoridad frente a todos los aspectos de una obra.

Esta situación de dependencia, evidente subordinación a voluntades, criterios e intereses generalmente discutibles rebajan la calidad del trabajo profesional y deterioran el prestigio y el respeto que la profesión merece.

$\mathrm{El}$ arquitecto, que fue director de la orquesta, se ve ahora reducido a tocar, según la batuta de otra autoridad, un solo instrumento: el proyecto, que gracias a la ley todavía no se le ha podido quitar. fuan Agustín Soza: Muchas veces el cliente no está dispuesto a arriesgar sus referencias ya comprobadas; sin embargo, con la pasión con que muchos arquitectos logran dar a entender sus propuestas, apoyados en experiencias de obras construidas en Chile y en otras partes del mundo, las personas están más dispuestas a recibir nuevas ideas y atreverse a experimentar con nuevos espacios, formas y materiales.

Mario Carreño: Hay una dificultad económica por el sistema de oferta-demanda-precio como regulación, en donde la oferta de arquitectos es alta... Diría que una expectativa que no teníamos pero que ha aparecido como virtud y dificultad del ejercicio profesional es el descubrimiento de la relación con el cliente, esta intimidad durante el desarrollo de un proyecto y la construcción de la obra. Cada obra es una visita larga, se podría decir. Miguel Eyquem: El ejercicio profesional está equivocado, está mal planteado, no tiene estatura. El arquitecto hoy en general es un empleado del 
sistema de la inversión inmobiliaria. Si gana un concurso debe ponerse al servicio de la institución que lo financia. La introducción de la no cultura en el campo de la arquitectura es su aniquilación. Los mecenas clásicos influían, exigían, etc. como todo poder lo hace. Bien distinta era esta intervención a la que se genera hoy día. No sólo por diferencia de cultura sino por una incomprensión profunda del proceso: quiénes son los actores, cuál es la inteligencia del operar empresas de grandes capitales en juego. Es decir, operaciones importantes emprendidas sin una visión clara, con alcance, con una mirada penetrante hacia adelante. La edificación es un factor del urbanismo, la construcción y perfeccionamiento de la ciudad. Esto requiere una visión a largo plazo. Todo lo demás es improvisación falsa que lleva a los desastres que sobrevivimos cada día.

De este modo el arquitecto, quien no interviene en la gestión económica, resulta ser el peón de este ajedrez. Como por último no es un técnico, y no debe serlo, no se le confiere ninguna autoridad, él se ha encargado de perderla con su conducta individualista. Su misión, si se le concediera alguna, muchas veces es prescindible. En el mejor de los casos, por medio de una amistad en el sistema, podría atribuírsele la gestión de árbitro del buen gusto, el de las convenciones en boga (de todas maneras discutido, desprestigiado por otros intereses).

Entonces: arquitecto sin real oficio reconocido, sin autoridad, ¿qué recibe en retribución? el más pequeño honorario del sistema: se considera que éste es su valor.

Sebastián Irarrázaval: Comparada con otros países, la evaluaría como afortunada. Existe una cierta sofisticación en los clientes y por tanto, existe aún campo para la experimentación.

3. ¿Cuáles son las debilidades y fortalezas en la educación del arquitecto? En este contexto, ¿qué significaría la posesión de un posgrado? Albert Tidy: Pienso que en general la educación de un arquitecto es confusa, especialmente en los primeros años de formación. Siempre me ha parecido sospechosa la relación forzada entre poesía y arquitectura. Pienso que antes de escribir un texto hay que conocer las palabras, y antes el abecedario; sólo entonces se pueden expresar las ideas. Una vez alcanzado el nivel de instrucción básica, la universidad no debe ser un lugar de traspaso de conocimientos, sino un lugar de búsqueda, pues creo en la autoinstrucción. Sobre todo hoy que existe una mayor disponibilidad de información, más barata e inmediata. Los ejercicios de taller deben ser preguntas, donde se conoce el origen pero se ignora el resultado.

Arturo Torres: La gran fortaleza que tiene la tradición de la enseñanza arquitectónica es la posibilidad de creatividad: la utilización positiva del pensamiento caótico, aprender a solucionar problemas complejos desde un acervo cultural plural y relativamente asentado. Por otro lado su debilidad es tanto su incapacidad de lograr una comunicación universal del conocimiento descubierto (como aquella que existe en las ciencias exactas) como tampoco de acumular sistemáticamente este conocimiento para ponerlo al servicio de logros mayores.

Bernardo Valdés: Al egresar uno percibe que los tiempos propios de la disciplina son distintos a los que se le exige. Justamente, un posgrado no significa más -ni menos- que haber tenido un poco más de tiempo para mirar con detención un cierto entorno.

Carolina Del Campo: Creo que al igual que cuando salí de la universidad sigue existiendo una disociación entre los ramos que son taller y los otros ramos.

Creo que dentro de la formación de un arquitecto se deben suplir muchas demandas que no estuvieron cumplidas en los colegios, como la formación de liderazgo y autonomía. En este sentido creo que los profesores de taller no sólo debieran estudiar arquitectura, sino también educación.

Enrique del Río: El medio más eficaz son los profesores y sus testimonios como personasarquitectos, no tanto la malla o currículo.

En este sentido me cuesta ver un posgrado ya que lo más importante se juega en el pregrado. Sí tendría sentido realizarlo después de unos años, como un retiro, como una detención para pensar lo que se está haciendo profesionalmente.

Fuan Agustín Soza: Un posgrado lo tomaría después de algunos años de ejercer la carrera, para tener mayor claridad de mis necesidades y falencias en el ejercicio de la arquitectura. En este momento como prioridad está ejecutar proyectos, porque pienso que es allí donde está el real aprendizaje.

Mario Carreño: He tenido la suerte de estudiar en la escuela de la U.C.V. mis dos primeros años y en la U.C. los restantes hasta el título, y durante estos primeros años de ejercicio profesional independiente la memoria de los profesores y los estudios de ambas escuelas está despierta, y relacionada, en el trabajo diario como arquitecto.

Creo que ese es el valor que trae un estudio de postítulo. Por un lado la profundidad en el talento de cada cual, y por otro abrir el campo de la formación a una mirada que pone en relación distintas maneras de aproximación a los asuntos que se estudian.

Renato D'Alençon: Dilapidamos de nuestra formación la capacidad de síntesis en la comprensión de los problemas, y la capacidad de proponer soluciones del mismo modo, sintéticas e integradoras. Esto me parece es un aporte sustantivo en el que tenemos potencialmente una considerable ventaja. Un arquitecto es capaz -por formación- de articular un problema en su complejidad y con su contexto en una síntesis que le permite, más que resolver, plantear problemas de manera integrada.

Sin embargo, esta capacidad de síntesis carece a menudo de una plataforma de conocimientos relevantes que permita participar en ámbitos de decisión distintos de aquél en el que estamos acomodados.

Marco Polidura: La poca relación con la realidad, a pesar de los esfuerzos por integrar a los alumnos a ella, y por otro lado la gran cantidad de materias que se aborda, son a la vez la debilidad y fortaleza de nuestra educación.

De todas maneras creo que lo verdaderamente importante y lo que forja la actividad del arquitecto es su carrera profesional; la conexión entre los estudios y la realidad es lo que permite lograr el desarrollo real de temas reales. ARQ 